\title{
Fxploring the sex differences in atrial fibrillation and stroke in a cohort of 1178 patients with 10 year follow up.
}

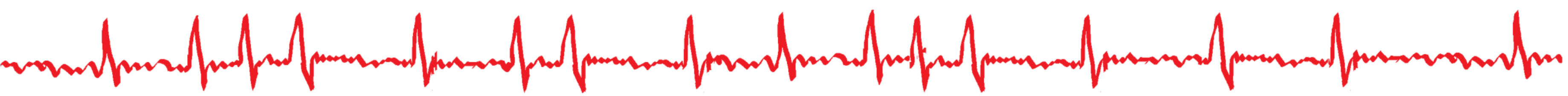

\section{Method}

A well-described stroke cohort was included between 1998-2001. Discharge diagnose of either ischaemic stroke or Transitory Ischaemic Attack (TIA) was selected for the analysis $(n=1178)$. Known and found risk factors as well as results of the examinations were registered. A 10-year follow up was performed focusing on vital status, atrial fibrillation (AF) and reoccurrence of ischemic stroke or TIA.

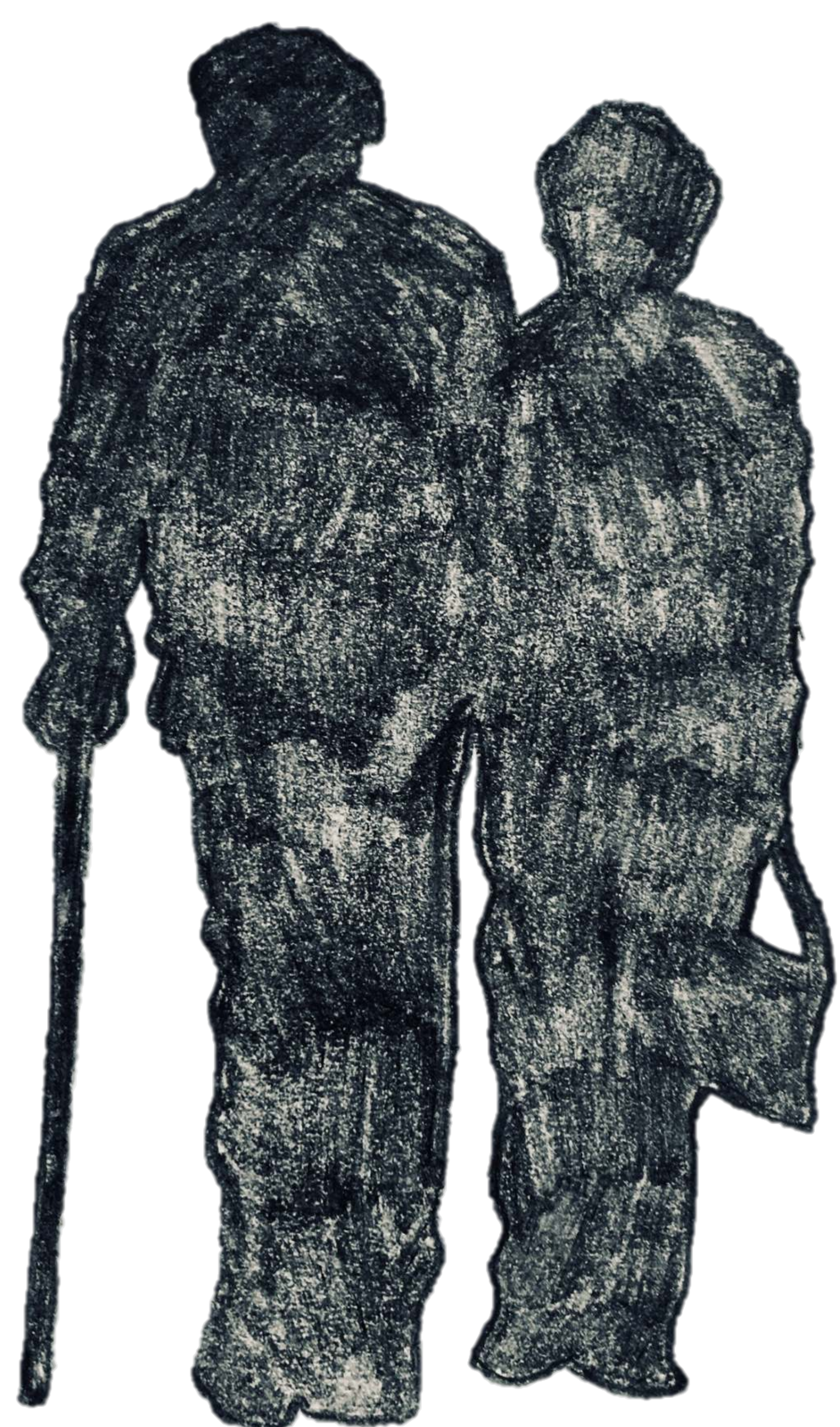

\section{Results}

The distribution of men and women was equal as well as the ratio of TIA and ischaemic stroke (75.2\% vs $75.7 \%$ ischaemic stroke women vs men).

\section{The women were significantly older} (75 vs 69) $\mathrm{p}<0.001$ )

AF was known or found in $\mathbf{2 1 . 1} \%$ of the women vs $15.1 \%(P<0.001)$, At 10 years follow-up, AF was reported in $36.7 \%$ of women and 26.5\% of men ( $P<0.001)$

Diabetes was present in $10.6 \%$ of the women vs $17.1 \%$ of the men $(\mathrm{P}<0.001)$ Hypertension and vital status at follow-up was not significantly different in the two groups.

\section{Conclusion}

Atrial fibrillation is far more prevalent in women with ischaemic stroke/TIA than men; women with $\mathrm{AF}$ are older than men and differ in risk factor profile.

Rates of $\mathrm{AF}$ increases further during long term follow up reaching the highest frequency in women.

Personalised medicine in secondary stroke prevention could be an answer to the increasing evidence of gender differences in stroke and should be explored. 